\title{
Rethinking context as a social construct ${ }^{\text {th }}$
}

\author{
Varol Akman* \\ Department of Computer Engineering and Information Science, Bilkent University, \\ Bilkent, Ankara 06533, Turkey
}

Received 10 February 1998; revised version 13 May 1999

\begin{abstract}
This paper argues that in addition to the familiar approach using formal contexts, there is now a need in artificial intelligence to study contexts as social constructs. As a successful example of the latter approach, I draw attention to 'interpretation' (in the sense of literary theory), viz. the reconstruction of the intended meaning of a literary text that takes into account the context in which the author assumed the reader would place the text. An important contribution here comes from Wendell Harris, enumerating the seven crucial dimensions of context: knowledge of reality, knowledge of language, and the authorial, generic, collective, specific, and textual dimensions. Finally, two recent approaches to interpretation, due to Jon Barwise and Jerry Hobbs, are analyzed as useful attempts which also come to grips with the notion of context.

It must be noted that there has been a considerable body of contributions connecting linguistic structure with social context. For example, anthropological linguistics, from Bronisław Malinowski onwards, has underlined the cultural context of discourse as essential to meaning. This viewpoint became prominent with the emergence of the ethnography of speaking in anthropology. Thus, conversation analysis represents a consistent formal effort to contribute to an analysis of the nature of context. While this paper emphasizes and reviews the literary theory approach, it makes various contacts with works of the latter kind (e.g., the landmark contributions of Erving Goffman, John Gumperz, William Hanks, John Heritage, Dell Hymes, et al.) in order to deliver a more balanced and complete study of the dimensions of context. (C) 2000 Elsevier Science B.V. All rights reserved.
\end{abstract}

\footnotetext{
An early version of this paper was presented at the AAAI-97 Fall Symposium on Context in Knowledge Representation and Natural Language, Massachusetts Institute of Technology, Cambridge, MA (November 8-10, 1997). I am grateful to Prof. Graeme Hirst, one of the invited speakers, for encouragement; his symposium paper (Hirst, 1997) was a source of inspiration. I also thank Prof. Jacob Mey for his understanding and an anonymous referee for criticism which contributed to making this a more complete paper. Obviously, I am solely responsible for the final content. For a brief rendition of some of the issues studied here, see Akman (1994).
}

*Phone: +90 312 290-1537; Fax: +90 312-266-4126; E-mail: akman@cs.bilkent.edu.tr 
Keywords: (Situated) context; Interpretation; Belief system; Genre; Literary theory; Anthropological linguistics

\section{Introduction}

"Every great, liberating idea inevitably becomes a straight-jacket in time", Hegel once quipped. Nothing can be truer in the case of artificial intelligence (AI) approaches to context, already a key concept in the fields of semantics, pragmatics, ethnographical studies of language use, and so on.

Starting with McCarthy's celebrated article (1987) which formulated the need for and a glimpse of formal contexts, a great majority of the AI-based works on context had a logical - thus, to some extent, computational - character. (The reader is referred to Akman and Surav, 1996, for a reasonably detailed review of these.) While this tendency is healthy and of fundamental importance, it is important to note that other academic disciplines, such as linguistics, philosophy, anthropology, etc., have also studied various aspects of the context phenomena. By just limiting their attention to formalized contexts, AI researchers are committing a grave mistake because it looks like there is only so much one can say about formalized contexts (Akman and Surav, 1997; McCarthy and Buvač, 1997). Therefore, I believe that any serious progress in further delineating the notion of context will have to borrow from the afore-mentioned disciplines, and additionally, from psychology and literary theory. Clark's recent books (1992, 1996), which argue that language use embodies both individual and social processes, may be regarded as fine examples of the contribution the former discipline (psychology) can make to the scientific study of context. It is my intention to consider the latter discipline (literary theory) in this paper. Specifically, I want to recast a book, Harris (1988), and two papers in literary interpretation, Barwise (1989) and Hobbs (1990), and explain what important observations they include vis-à-vis context.

While the central theme of this paper is thus literary theory, earnest attention is paid to prominent areas such as anthropological linguistics, ethnomethodology, and sociolinguistics, for they also make consistent efforts to connect linguistic structure with social context. From Malinowski onwards, the sociocultural context of utterances has been regarded as crucial to meaning (and action); with the emergence of the ethnography of speaking within the discipline of anthropology, this perspective has been largely established. Sacks' concern with the contextual sensitivity of language use in a variety of social relations has been at the center of his 'conversation analysis' right from the start. All these studies have solidified the contribution of cultural contextualization to the understanding of language (Goodwin and Duranti, 1992). This is why the relationship between language and sociocultural order is something of which I take cognizance in this paper.

\section{Context as a garbage can}

In an article written almost 20 years ago, Clark and Carlson (1981: 313) noted that "[a]lthough the notion of context plays a central role in most current explana- 
tions of language understanding, what can count as context is generally undefined". I think that this situation has changed considerably; besides, now we probably have a better idea why we need to define and circumscribe the extent of context. For, again in the words of Clark and Carlson (1981: 313), "[i]f it [context] includes any information a listener can make available to himself, then it loses much of its power to explain" (my emphasis). That context has become a favorite word in the vocabulary of cognitive psychologists and that it has appeared in the titles of a vast number of articles are well-known facts. This is why Clark and Carlson complain that the denotation of the word has become murkier as its uses have been extended in many directions. Not surprisingly, they deliver the now widespread opinion that context has become some sort of 'conceptual garbage can'.

According to the Oxford English Dictionary the term 'context' usually has two primary meanings: (i) the words around a word, phrase, statement, etc. often used to help explain (fix) the meaning; (ii) the general conditions (circumstances) in which an event, action, etc. takes place. Clearly, the first meaning is closely related to linguistic meaning and linguists' use of the term, whereas the second - more general meaning is the one which is closer to a desirable account of context in AI. (It is commonly thought that the main AI uses of formalized context will be in connection with reasoning about the effects of goal-oriented actions.)

In a dictionary of philosophy (Angeles, 1981), the same term is defined, reflecting the latter desideratum more satisfactorily, as follows:

Context (Latin contexere, 'to weave together'): The sum total of meanings (associations, ideas, assumptions, preconceptions, etc.) that (i) are intimately related to a thing, (ii) provide the origins for, and (iii) influence our attitudes, perspectives, judgments, and knowledge of that thing.

In another dictionary (Collins Cobuild English Language Dictionary), the prevalent meanings of the term include the following:

- The context of something consists of the ideas, situations, events, or information that relate to it and make it possible to understand it fully.

- If something is seen in context or if it is put into context, it is considered with all the factors that are related to it rather than just being considered on its own, so that it can be properly understood.

- If a remark, statement, etc. is taken or quoted out of context, it is only considered on its own and the circumstances in which it was said are ignored. It, therefore, seems to mean something different from the meaning that was intended.

Context is also a crucial factor in communication. Ordinary observation proves its importance in assorted ways. Just consider the confusion which results from lack of contextual information when, for example, I join a scheduled meeting half an hour late. Without clues of the original context, I might find it hard to make sense of the ongoing discussion. In any case, the discussants would realize that they cannot assume a lot about the background knowledge I possess and would normally give me a quick rundown of the conversations so far. This is essentially the view of Clark and Carlson (1981), who regard context as information that is available to a person for interaction with a particular process on a given occasion. Their intrinsic context is an attempt to capture the information available to a process that is potentially necessary 
for it to succeed. The intrinsic context for grasping what a speaker means on some occasion is the (limited) totality of the knowledge, beliefs, and suppositions that are shared by the speaker and the listener, a.k.a. the common ground (Clark et al., 1983).

Can there be a notion of sentence meaning that is independent of context, i.e., a level at which a given sentence has a single meaning, but may be employed for different purposes? I believe that the answer many semanticists usually give to this question is at least partly in the affirmative. In fact, according to orthodox semantic theory (Allen, 1995: 228), there is a representation of context-independent meaning called the logical form, and the aim of semantic interpretation is simply to map a sentence to its logical form. While this approach yielded many useful results for the toy examples of semantic theory - especially in regard to indexicals and definite descriptions; see, e.g., Cresswell (1996) - I think it is misdirected in general and cannot really be of much use in an AI-based study of context. For example, it has been pointed out numerous times that even sentences such as 'The cat is on the mat' require a minimal (non-empty) set of background conditions, e.g., that the earth's gravitational field is in effect, that the mat is lying flat, that the mat is a standard (normal size) mat, and so on. In the words of Fish (1980: 310):

"It is impossible even to think of a sentence independently of context, and when we are asked to consider a sentence for which no context has been specified, we will automatically hear it in the context in which it has been most often encountered." (my emphasis)

\section{Setting out the sociocultural scene}

It turns out that strong analytic frameworks focusing on assorted aspects of context have been contributed by researchers working in a number of different fields including anthropological linguistics, ethnomethodology, and sociolinguistics (Drew and Heritage, 1992).

Hymes developed the concept of communicative competence (1972) and his celebrated SPEAKING model $(1974,1986)$ to encourage a cultural approach to the analysis of discourse. His categories - enumerated below - are sophisticated enough to analyze various kinds of discourse:

[S]etting and scene: The former refers to the time and place of a speech act whereas the latter is the psychological setting or 'cultural definition' of a scene. For instance, the faculty club might be the setting for a talk commemorating the late Prof. $X$. The range of formality would change according to the content of the talk.

$[P]$ articipants: These include the speaker and audience (addressees plus other hearers). At the faculty club, the waiter, although not addressed by the speaker, might also hear parts of the talk.

[E]nds: This refers to the purpose of the discourse. The goal of the commemorative event is to honor Prof. $X$ posthumously.

[A]ct sequence: This is the format and order of the series of speech events which make up the speech act. The talk might begin with an enumeration of the achieve- 
ments of Prof. X. Once the talk is over, an applause follows and Prof. X's daughter is invited to receive a plaque.

[K]ey: These are the cues that establish the tone of the speech act. In an attempt towards playfulness, the speaker at the faculty club may employ the lecturing format of Prof. X and may play with his glasses in the inimitable style of Prof. X.

[I]nstrumentalities: These are the forms and styles of speech. The speaker at the club will probably talk casually but may choose to use carefully prepared grammatical forms, if say, the president of the university is present.

[N]orms: These refer to the social rules governing the event and the participants' actions. In the faculty club, interruptions and contributions by the audience may be permitted. In a more formal event, 'no interruptions' would probably be the standard.

[G]enre: This includes assorted categories such as poem, myth, tale, proverb, riddle, curse, prayer, oration, lecture, commercial, form letter, editorial, etc.

Another contribution coming from sociolinguistics is Gumperz's contextualization cue (Gumperz, 1992). He maintains that a given aspect of linguistic behavior (e.g., lexical, prosodic, phonological, etc.) can function as a cue, indicating those aspects of context which are to be taken into account to interpret what is said by a speaker. Contextualization cues hint at relevant aspects of the social context (via particular codes, styles, and dialects), thus enabling participants in a discourse to reason about their respective communicative intentions and purposes (Gumperz, 1982, 1990). The notion of contextualization cue may be regarded as an important formal device, helping us to understand the relationship between language use and speakers' contextual reasoning. After all, it is a particular type of indexical, which (in combination with other cues and structural properties of an utterance) brings about a certain interpretation of the utterance (in a context). Gumperz (1993) offers a case study of how differences in the use of contextualization cues between a native speaker of English and a non-native, yet fluent speaker of English cause a serious breakdown in communication.

Even if speakers employ basically the same language, the rules for its usage would differ according to age, gender, ethnicity, class, etc. (Garfinkel, 1967). Accordingly, there is a healthy parallelism between Gumperz's linguistic concept of contextualization cues and Goffman's sociological concept (1974) of a frame. Goffman studies the 'definition' which participants give to a given social activity. His notion of frame focuses on what is going on, what is the situation, what are the participants' roles in this situation, etc. Goffman's affiliated notion of footing (1981) refers to the dynamic character of frames, i.e., the evaluations (respectively, redirections) made (respectively, adopted) by the participants in passing from one frame to another.

Being social concepts that converge on the organizational aspects of individuals' conduct, Goffman's frame and footing are interesting in their own right. But, more importantly, they are linguistically relevant: participants in a discourse negotiate frames and, using discourse cues and markers, affect changes in footing.

Surely, a given context not only 'legislates' the interpretation of indexical elements; indexical elements can also mold the background of the context. Ochs (1990) 
gives an example from Japanese culture where the affective dimension of a context can be enriched by the use of particular indexical elements to fabricate particular types of social identities.

Silverstein (1992) also demonstrated how treatments of context in "deterministic theories of syntactic structure, or deterministically computable notions of semantics/pragmatics" run into inescapable and indomitable problems because it [context] is forever unbounded, accountable in indefinitely many ways, and limitlessly defeasible. Silverstein has two construals of contextualization. In the narrower construal, a text is read by taking all denotation as potentially indexical, relative to the "surround' context and the sociocultural context. In the wider construal, one takes the stance of those social sciences that locate the object of investigation in societies and social groups. The aim is to seek to know how language use indexes (and hence brings into contextual reality) those implicit values of relational identity and power (i.e., culture, in the social anthropological sense).

Schegloff (1991) distinguished between two types of context in the social and human sciences, especially with respect to interaction and discourse. The external (distal) context includes aspects of social life central to the social sciences (e.g., the class, ethnic, and gender composition of an interaction). The discourse (proximate) context is the sort of sequences of talk or courses of conduct in which particular events may occur (stories, etc.) and interactants act, relative to the episode in progress (e.g., as the narrator of a story).

\section{The experiential nature of context}

Considerations such as those in the preceding section suggest the useful heuristic that 'experience' may be a comprehensive synonym for 'total context', because "only that which has entered our experience is available to aid us in interpretation" (Harris, 1988: 78). Clearly, this experience is a social and cultural construct: it is shaped and obtained by an individual growing up within the confines of a society. Suzuki (1984) notes that the culture of a country affects all aspects of the life and thought of the people living in that country. Jahoda (1997: 37) states that social institutions are all "cultural components that a growing child gradually absorbs". She further argues that informal institutions (customs, traditions, etc.) are crucial in that they become "individual habits, a part of one's own identity that is shared with all who belong together". Similarly, take the following remarks of Auster (1995: 140):

\footnotetext{
"The text is no more than a springboard for the imagination. 'Once upon a time there was a girl who lived with her mother in a house at the edge of a large wood.' You don't know what the girl looks like, you don't know what color the house is, you don't know if the mother is tall or short, fat or thin, you know next to nothing. But the mind won't allow these things to remain blank; it fills in the details itself, it creates images based on its own memories and experiences - which is why these stories [fairy tales] resonate so deeply inside us." (my emphasis)
}

Auster uses considerations of the above sort to explain why his own writing style, one that is frequently devoid of descriptive passages and the background that char- 
acterize the typical novel, is still able to create full-fledged worlds. Having been influenced by fairy tales (the Brothers Grimm, the Thousand and One Nights, etc.), his works communicate in the most economical way large amounts of information simply because, he thinks, the reader is able to supply the details based on her own memories and experiences. In short, "[ $\mathrm{t}$ ] he listener becomes an active participant in the story" (Auster, 1995: 140).

Notice that the experiential nature of context can cause bona fide confusions for the participants in a 'discourse'. The following example comes from ethnomethodology (Sacks, 1992: 473):

\begin{abstract}
"On one occasion he [Phineas, a four-year old child] and other children had made a 'ship' in the schoolroom, with an arrangement of tables and chairs. Phineas' part in this was comparatively a passive one, as he was but a 'passenger' on the ship, and was going on with his own pursuits on the voyage, sitting at a table and sewing a canvas bag. Miss D. was with him 'in the ship', and all around them the crew and the captain carried on the business of the voyage. And when, presently, a new supply of thread was wanted, and Miss D. said to Phineas "Will you get it out of the drawer?" Phineas replied "I can't get out of the ship while it's going, can I?" and called out in a stentorian voice to the "captain," "Stop the ship, I want to get out". After some demur, the ship was brought into a "landing stage' and Phineas got out, secured his thread, and got in again, saying "Now it can go again'."
\end{abstract}

In the reported scene, two agents $A$ and $C$ (Miss D., adult, and Phineas, child), are individuating the reality in two different ways. C's account of it as a boat scene is at odds with $A$ 's account of it as an imitative game, i.e., a game where kids simulate some real environment in their play. $C$, being totally immersed in the game, does not see that in games rules can be violated, whereas $A$ is able to 'switch' to the more realistic context whenever there is such a need. Here is another, similar piece of data mentioned by Sacks (1992: 473):

\footnotetext{
"She [a five-year old girl] looked up at me expectantly, anticipating that I [the teacher] would push her. I said firmly, "No. Put your knee in the wagon and you can push yourself". She sat several seconds, obviously waiting for me to push her. She waited long enough to be certain I wasn't going to push. Then she got down, put one knee in the wagon and the other on the floor of the cement porch, getting ready to push herself. In order to encourage her I said "Come on". She didn't move. She looked straight ahead. She announced, "There's a car coming". Then she looked at me indignantly. She was seemingly disgusted that I couldn't see this car that she announced. An imaginary car was coming, and she had to wait for it to get out of the way."
}

Again, the teacher is assuming that the little girl can do the pushing act by just leaving the play context for an instant. The girl, on the other hand, is determined to stay within the game context and take the requisite precautions such as minding an approaching car. The contexts of the teacher and the student are at a clash.

In light of these (and numerous other) observations of Sacks, it is fruitful to take social knowledge to be a significant component of contexts (Devlin and Rosenberg, 1996). In a nutshell, the 'ethnography of speaking' framework has clarified the contribution of cultural contextualization to the understanding of language. More generally, it has thrown considerable light on the relationship between language and the sociocultural order. 


\section{Harris's seven dimensions of context}

"[I]n the construction of a satisfactory theory of context, the linguist's account of the interpretation of utterances must of necessity draw upon [...] the theories and findings of the social sciences in general", suggests Lyons (1995: 292). In the true spirit of this suggestion, Harris (1988) surveyed the multitude of interacting kinds of knowledge and awareness that make up the context. According to him, two principal dimensions of context are (i) world knowledge and (ii) knowledge of language. In case of (ii), the many facets of linguistic knowledge involving word repetitions, abnormal ordering, etc. bring unusual complexities of meaning, as the following excerpt from Charles Olson's poem I, Maximus of Gloucester, to You illustrates:

But that which matters, that which insists, that which will last

where shall you find it, my people, how, where shall you listen

when all is become billboards, when all, even silence, is

when even the gulls,

my roofs,

when even you, when sound itself

As for (i), Leech (1981: 69) notes that the study of interpretation in context involves encyclopedic knowledge of the world - which, he concedes, cannot be practically included in the study of semantics - and gives the following example:

"[I]t is relevant to the interpretation of the sentence "Shall I put the sweater on?" to know whether anyone has yet invented a sweater warmed by an electric current."

Harris enumerates five additional dimensions of context. These are the (iii) authorial, (iv) generic, (v) collective, (vi) specific, and (vii) textual dimensions. The authorial dimension arises from the body of available information about the author and is clearly crucial in reconstructing the meaning of a text. Some authors do expect a prospective reader to be knowledgeable about particular pieces of information about themselves. For instance, the casual reader of Soft Machine (by William Burroughs) will be doing a better job of interpretation when she knows that the work has an autobiographical character and that the narrator in the following opening paragraph is Burroughs himself (Burroughs, 1980):

"I was working the hole with the sailor and we did not do bad. Fifteen cents on an average night boosting the afternoons and short-timing the dawn we made out from the land of the free. But I was running out of veins." (Burrows (1980: 9))

By the generic dimension, Harris hints at genre, i.e., the category of literary text characterized by a particular style, form, or content (cf. the SPEAKING model of Hymes, discussed earlier). It is clear that formulae like 'Once upon a time ...' are framing devices, or 'markers of footing' in Goffman's terms. They are most conveniently regarded as indexes of the genres which the speaker is producing or invoking. (They can also be seen as kinds of contextualization cues in the sense of Gumperz.) 
The author's intent to write will necessarily involve some notion of genre (poem, novel, detective story, etc.) and he will most probably employ the conventions of his chosen genre to help the reader assign the proper interpretation (Kessler et al., 1997). That is probably why an academic paper usually invokes a well-known framing device associated with that genre, namely, extensive references. To take a different example, in the following poem (For Hettie, by LeRoi Jones), humor is certainly part of the author's intent and is achieved by parodying the use of proper English:

My wife is left-handed.

$[\ldots]$

[...] I sit

patiently, trying to tell her

what's right. TAKE THAT DAMM

PENCIL OUTTA THAT HAND. YOU'RE

RITING BACKWARDS. \& such. [...]

It may be thought that awareness of genre cannot be easily achieved unless the reader is knowledgeable about the definitions and commentary of literary historians, e.g., 'a sonnet is a lyric poem written in a single stanza, which ... etc. etc'. This seems highly questionable. There has been considerable work in conversation analysis and anthropological linguistics on 'genre as practice' (see for example Hanks, 1987). Hanks (1996) demonstrates that the social role of the shaman in curing ceremonials in Mayan culture is essentially connected to his skill to recite text fragments of a particular genre, possessed by him, and appropriately called curing chants. Now, the shaman enacts these texts in the (ritual) context of curing, which, to a considerable extent, is built by the very enaction of them. Hanks's result is perhaps a natural one in that the dynamic, socially constitutive qualities of context are unavoidable: each incremental act within an interaction updates the existing context and prepares new ground for subsequent interaction.

Harris regards the collective dimension as crucial for the following reason. Leaving the co-textual ambiguities aside (for they are rather well-understood, thanks in part to semantic theory), contextual ambiguities are usually born out of a misplaced belief on the part of the author that the reader has access to the author's collective dimension. The author usually assumes that his imaginary reader has a general grasp of the relevant social institutions, customs, norms, etiquette, topical news items, and cultural and historical facts. Harris (1988: 107) notes that:

\footnotetext{
"Such collective knowledge is the subject of investigation from a variety of disciplines: socio-linguistics, ethnomethodology, the sociology of knowledge. John Searle calls such knowledge and awareness 'factual background information'; Charles Altieri calls it the 'cultural grammar'; [Kent] Bach and [Robert] Harnish speak of 'mutual contextual beliefs'; socio-linguists like Dell Hymes speak of the 'ethnography of communication'. Since we also know that we don't all share the same knowledge, we constantly make judgments about how much and what sort of background information or cultural grammar persons to whom we are speaking or writing are likely to possess."
}

The specific dimension - in contrast to the collective dimension, which attributes knowledge to the anticipated reader - comprises elements that are specific to the sit- 
uation in which a discourse occurs. Harris enumerates five interdependent aspects of the specific dimension (1988: 112):

"1. The physical situation: A porch in the second Sacks example given earlier.

2. The psychological conditions of the discourse participants: The teacher is indifferent and the little girl is angry and fearful, in the same example.

3. The socio-cultural relationship: Teacher/student, in the same example.

4. Interpersonal awareness: Specific personal knowledge of shared experiences, close to nil in the same example. I have already noted earlier that interpersonal awareness receives a fine treatment in Clark and Carlson (1981). Their proposal is that when a listener tries to understand what a speaker means, the process she goes through can be explained in terms of a common ground - the knowledge, beliefs, and suppositions that the two share in a technical way.

5. For any sentence, the immediately preceding ones: Obvious."

Finally, the textual dimension refers to the totality of arguments, events, actions, and so on, in the way these are given in the text. A coherent text is in fact a system of interlocking subtexts, whose interpretations against the unfolding whole make small contributions to the meaning of the complete text. The process is, borrowing T.S. Eliot's words, one with 'hundred indecisions' and 'hundred visions and revisions', as the following excerpt explains (Harris, 1988: 119):

"As the text unrolls, there is not only the cumulative build-up of effect through the linking of remembered earlier elements to the new one. There is sometimes a backward flow, a revision of earlier understandings, emphases, or attitudes; there may even be the emergence of a completely altered framework or principle of organization."

That the interactional context is continually being developed with each successive action is an observation Heritage (1984) also made. According to him, utterances and the social actions they embody are treated as doubly contextual. First, utterances and actions are context-shaped. This simply means that their contributions cannot be adequately appreciated unless the context in which they operate is taken into account. Second, utterances and actions are context-renewing. Every utterance will form the subsequent context for some following action in a sequence; it will thus contribute to the contextual framework which lets one understand the next action. Additionally, each action will function to renew context, where 'renewal' is understood as one or more of the processes of maintaining, adjusting, altering, and so on.

\section{Context and disambiguation}

It is heartening to find echoes of Harris' observations in other works. For example, Crystal (1991: 78-79) also assumes that context encompasses the total linguistic and non-linguistic background of a text. The linguistic aspects are widely known; they include the specific parts of a text surrounding a unit (e.g., a word) which is the focus of attention. The non-linguistic aspects (which Crystal calls the situational context) include the immediate situation in which the unit is employed, and the awareness by the author and reader of what has been said earlier plus the pertinent 
belief system (i.e., those beliefs and presuppositions germane to the text at hand). Here's another concise description of this two-fold character of context, this time coming from Blackburn (1994: 80):

"In linguistics, context is the parts of an utterance surrounding a unit and which may affect both its meaning and its grammatical contribution. [...] Context also refers to the wider situation, either of the speaker or of the surroundings, that may play a part in determining the significance of a saying. Sometimes the term co-text is used for the narrow, purely linguistic context."

An author assumes that a reader will try to obtain a coherent interpretation of his text. In order to facilitate this, he provides help as to which contextual dimensions are relevant. If there is information the reader is not presumed to have, the author makes it available using assorted devices. But in the end, we can never be certain about the authorial intention; the best we can do as a reader is to assess probabilities. Accordingly, the so-called disambiguating role of context should be taken with a grain of salt. While it is true that the most useful role context plays is in the disambiguation of authorial meaning, this disambiguation will at best attach a certain probability to each available alternative reading (or sense). (Needless to say, a totally ungainly alternative would have zero probability assigned to it.) In the words of Leech (1981: 66 and 68, respectively):

"[The] specification of context (whether linguistic or non-linguistic) has the effect of narrowing down the communicative possibilities of the message as it exists in abstraction from context. (my emphasis) [M]eaning-in-context should be regarded as a narrowing down, or probabilistic weighting, of the list of potential meanings available to the user of the language." (my emphases)

In fact, Leech illustrates the matter by just studying in the sentence 'Shall I put ... on?' the various senses of the dictionary entry 'put ... on', namely (i) 'switch ... on', (ii) 'put ... on oneself' (i.e., 'don ...'), and (iii) 'place ... on top of something else'. If we now put 'the blanket' instead of '...' then there is considerable potential for our sentence to have any of the above three senses. If '.. ' is replaced with 'the portable radio' then the first sense overrules, although there is a considerable potential for the third sense to be applicable, and as expected, a very small possibility for the second sense. If 'the lump of wood' is substituted for '...' then none of the first and second senses stand more than a minute chance and the third sense clearly overrules.

My favorite example demonstrating why we cannot take a text and settle on an interpretation without making certain assumptions about the contextual dimensions is due to Hobbs (1990: 26):

"When I first read the opening line of Shakespeare's 68th sonnet,

Thus is his cheek the map of days outworn,

I had a very powerful image of an old man whose face was deeply wrinkled. These wrinkles were like the roads on the map of the life he had led. Later I read the footnotes. 'Map' meant 'symbol'. 'Days outworn' meant 'ancient or classical times'. The line meant that his face was the symbol of classical beauty - almost the precise opposite of my interpretation. I had interpreted the line against a belief system that included knowledge of Rand-McNally road maps and beliefs about the romanticization of old age. The 
function of footnotes is to tell the modern reader something of the belief system Shakespeare must have assumed he shared with his Elizabethan reader." (my emphases)

Using Leech's approach, quoted above, we can reformulate this by saying that the interpretation achieved as a result of paying attention to the footnotes is the highly probable (consequently, the most authentic) one. Hobbs' own interpretation, while it had initially enough intuitive elements to justify it, is thus defeated and assigned zero probability in the end.

In the remainder of the paper, I take a quick look at the proposals of Hobbs (1990) and Barwise (1989), which also include the reader's belief system and the author's intention in elucidating the meaning of a literary work. While these two works have numerous aspects which overlap with Harris' theory, I will not explicitly highlight these coincidences but rather let the reader notice them.

\section{Hobbs and belief systems}

Hobbs assumes that the reader's interpretation procedure works by translating the text into some knowledge representation scheme (e.g., logical formulas) and then drawing inferences from her belief system so as to satisfy the requirements for a 'good' interpretation. He enumerates four crucial elements as belonging to the set of requirements:

1. There is a common ground, of the sort Clark and Carlson (1981) advocate, between the author and the reader.

2. There are constraints in effect which ease the interpretation of many instances of metaphor and metonymy. ('But metaphors do not automatically catch on and influence people; they have to fit in with a feeling in the air, or Zeitgeist, which differs from language to language', cautions Aitchison, 1997: 91.)

3. Different parts of the text should be taken as coherently interconnected, leading to a unitary structure for the whole. (This also explains in part the difficulties encountered in interpreting post-modern literature.)

4. The text should be related by the reader to her theory of what the author is trying to achieve.

Hobbs comes up with a formula which he thinks is applicable in general:

(1) $F(K, T)=I$

Here $F$ is an interpretation procedure employed by the reader. Hobbs believes that AI work in discourse analysis gave at least some indication what $F$ looks like. $T$ is the sequence of words that comprise the text; it is assumed to be given. (Hobbs puts forward an interesting account of how realistic this assumption is and how it may be disputed. I omit this discussion because it does not contribute to the problem at hand.) $I$ is the interpretation, i.e., a formal representation of the content of the text 
that satisfies the four points made above. Hobbs is especially careful about the fourth point (1990: 18):

"The text needs to be related to the [reader's] theory of what is going on in the environment. Typically, but not always, this includes the [reader's] beliefs about the author's intention, or more generally, the author's plan as it unfolds in time; the [reader] should try to relate the text to what the [reader] believes the author is trying to accomplish."

$K$ is the belief system and includes the whole range of beliefs, from naive knowledge about the physical world (Akman and ten Hagen, 1989) to interpretive conventions for assorted genres (Kessler et al., 1997). Basically, it is in $K$ the context is encoded.

Since $F$ and $T$ are assumed to be given in equation (1), we must determine $K$ and $I$. We have an equation with two unknowns. Hobbs suggests that the way we 'solve' the equation is via hypothesizing a $K-I$ pair. That is, we consider a particular interpretation $I$ of the text together with a belief set $K$ that will uphold $I$. (Hobbs calls the pair a theory of the text.) To decide among alternative theories of text, the reader tries to find the best $K$ and the best $I$, in the light of the four desiderata (for $I$ ) mentioned earlier.

\section{Barwise and authorial intentions}

Barwise (1989) sees all critical discourse as comprising one or more parts of the following triple: author, literary text, and reader (critic). The critic tries to capture what the author has created. In this endeavor, she assumes that the author's creative process finds its roots in the author's intentions. Barwise notes that the original intention and the 'achieved' intention may not coincide. During the creative process, what the author is trying to do is intentional. However, once the work is created, then we have something actual, so the critic should talk about the effect the work aims to evoke, the principles organizing the work into a whole, the meaning the work suggests, etc.

Like Hobbs (1990), Barwise provides an abstract equation formulating the relation between meaning and content:

(2) Content $_{R}(S, C)=P$

Here, $R$ stands for the conventions of the language, $C$ for the circumstances (context) shared by the speaker and listener (or the author and the reader), while $P$ is the propositional content the speaker wants to convey. The author's task is to find an expression $S$ that satisfies this equation. The task of the reader, on the other hand, is to determine $P$, given $R, C$, and $S$. All of the four parameters in equation (2) are at the speaker's disposal. He can 'adjust' them, as long as the equation is satisfied. Clearly, if the author experiments with $R$ - as in Joyce's Finnegans Wake or Burroughs' Naked Lunch - there is a lessened chance of his being understood, at least 
by the casual reader. (Unless, that is, the original text is accompanied by illuminating marginal notes and comments, pace Martin Gardner's annotated Alice's Adventures in Wonderland.)

The circumstances $(C)$ can be studied as four parts which possibly overlap:

1. Articulated constituents: This is what we have termed as co-text earlier. In general, it determines the interpretation of indexicals, among others. In the Burroughs example, the co-text contributes the narrator with ' $I$ '.

2. Unarticulated constituents: These are things whose existence follow. When the narrator says 'we did not do bad' in the Burroughs example, we understand that "we" stands for the narrator plus the sailor.

3. Articulated non-constituents: In the Burroughs example, when the narrator says that he was 'running out of veins', we infer that he was frequently doing junk, but this is not part of the content of what the narrator said.

4. Unarticulated non-constituents: In the Jones poem, the line 'My wife is lefthanded' suggests that there is a background convention in force in the narrator's world, whereby people writing with their right hands make up the standard set.

The reader of a literary text $(S)$ is faced with one equation having three unknowns: $R, C$, and $P$. As in Hobbs' equation (1), the solution may not be unique. The task of literary interpretation is to use the available information regarding the unknowns (e.g., biographical material about the author, information about the cultural setting in which the text was written, etc.) in order to limit the range of their possible values.

\section{Conclusion}

Not long ago, I was visiting Boston for a small workshop on (what else?) context. After a demanding morning session, I walked into the MIT Bookstore for a bit of shopping. Walking along the isles I noticed on a crowded shelf a little sign which read:

\section{$\Leftarrow$ NOAM CHOMSKY'S SECTION IS A LITTLE TO THE LEFT}

I found this fairly clever! In fact, my expectation that the workshop audience would also find the tongue-in-cheek message of this sign entertaining was fulfilled. When I referred to it at some point during my talk I got quite a few chuckles. But what kind of understanding did the author of the sign expect me (the reader) to have as a result of my seeing it? In treating this question in any detail, it was unavoidable for me to touch upon the notions of authorial intentions vis-à-vis sociocultural context.

On the other hand, I remembered that one of the common assumptions of early AI research had been that in order to build a commonsense reasoning system (say, a robot), some form of decontextualized meaning is necessary. In other words, all 
kinds of ambiguities must be dismantled from our terms and rules. Nowadays, we all know that this is not a realistic strategy. As Winograd notes (1990: 180):

"Such approaches work for the cases that programmers anticipate, but of course are subject to the infinite regress of trying to decontextualize context. The new terms or rules themselves depend on interpretation that is not represented in the system." (my emphasis)

In this paper, I have used several examples from literary theory to show that interpretation is possible only within shared contexts. Since such contexts necessarily have a social disposition, this paper can be seen as underlining the efficacy of a social sciences stance that is geared towards a better understanding of the 'magic' of context. I realize that this is difficult and, furthermore, not what the AI archetype would consider terribly interesting, but the bad news is that it is probably the only approach.

\section{References}

Aitchison, Jean, 1997. The language web: The power and problem of words. Cambridge: Cambridge University Press.

Akman, Varol, 1994. Ripping the text apart at different seams. Stanford Humanities Review 4(1): 31-34. [Special supplement: Bridging the gap (where cognitive science meets literary criticism), G. Güzeldere and S. Franchi, eds.]

Akman, Varol and Paul ten Hagen, 1989. The power of physical representations. AI Magazine 10(3): $49-65$.

Akman, Varol and Mehmet Surav, 1996. Steps toward formalizing context. AI Magazine 17(3): 55-72.

Akman, Varol and Mehmet Surav, 1997. The use of situation theory in context modeling. Computational Intelligence 13(3): 427-438.

Allen, James, 1995. Natural language understanding. Redwood City, CA: Benjamin/Cummings.

Angeles, Peter, 1981. Dictionary of philosophy. New York: Harper and Row.

Auster, Paul, 1995. Interview with Larry McCaffery and Sinda Gregory. In: P. Auster, The red notebook and other writings, 116-154. London: Faber and Faber.

Barwise, Jon, 1989. On the circumstantial relation between meaning and content. In: J. Barwise, The situation in logic, 59-77. CSLI Lecture Notes, 17. Stanford, CA: Center for the Study of Language and Information.

Blackburn, Simon, 1994. The Oxford dictionary of philosophy. Oxford: Oxford University Press.

Burroughs, William S., 1980. The soft machine, Nova express, The wild boys (Three novels by William S. Burroughs). A Black Cat Book. New York: Grove Press, Inc.

Clark, Herbert, 1992. Arenas of language use. Chicago, IL: The University of Chicago Press.

Clark, Herbert, 1996. Using language. New York: Cambridge University Press.

Clark, Herbert and Thomas Carlson, 1981. Context for comprehension. In: J. Long and A. Baddeley, eds., Attention and performance IX, 313-330. Hillsdale, NJ: Erlbaum. [Reprinted in Clark, 1992.]

Clark, Herbert, Robert Schreuder and Samuel Buttrick, 1983. Common ground and the understanding of demonstrative reference. Journal of Verbal Learning and Verbal Behavior 22: 245-258. [Reprinted in Clark, 1992.]

Cresswell, Max, 1996. Semantic indexicality. Dordrecht: Kluwer Academic.

Crystal, David, 1991. A dictionary of linguistics and phonetics. Oxford: Blackwell. [Third edition.]

Devlin, Keith and Duska Rosenberg, 1996. Language at work: Analyzing communication breakdown in the workplace to inform systems design. CSLI Lecture Notes, 66. Stanford, CA: Center for the Study of Language and Information. 
Drew, Paul and John Heritage, 1992. Analyzing talk at work: An introduction. In: P. Drew and J. Heritage, eds., Talk at work: Interaction in institutional settings, 3-65. Cambridge: Cambridge University Press.

Fish, Stanley, 1980. Is there a text in this class? Cambridge, MA: Harvard University Press.

Garfinkel, Harold, 1967. Studies in ethnomethodology. Englewood Cliffs, NJ: Prentice-Hall.

Goffman, Erving, 1974. Frame analysis: An essay on the organization of experience. New York: Harper and Row.

Goffman, Erving, 1981. Footing. In: E. Goffman, Forms of talk, 5-77. Oxford: Blackwell.

Goodwin, Charles and Alessandro Duranti, 1992. Rethinking context: An introduction. In: A. Duranti and C. Goodwin, eds., Rethinking context: Language as an interactive phenomenon, 1-42. Cambridge: Cambridge University Press.

Gumperz, John, 1982. Discourse strategies. Cambridge: Cambridge University Press.

Gumperz, John, 1990. Language and social reality. Cambridge: Cambridge University Press.

Gumperz, John, 1992. Contextualization and understanding. In: A. Duranti and C. Goodwin, eds., Rethinking context: Language as an interactive phenomenon, 229-252. Cambridge: Cambridge University Press.

Gumperz, John, 1993. Culture and conversational inference. In: W. Foley, ed., The role of theory in language description, 193-214. Berlin: Mouton DeGruyter.

Hanks, William, 1987. Discourse genres in a theory of practice. American Ethnologist 14(4): 668-692.

Hanks, William, 1996. Exorcism and the description of participant roles. In M. Silverstein and G. Urban, eds., Natural histories of discourse, 160-200. Chicago, IL: University of Chicago Press.

Harris, Wendell, 1988. Interpretive acts: In search of meaning. Oxford: Clarendon.

Heritage, John, 1984. Garfinkel and ethnomethodology. Cambridge: Polity Press.

Hirst, Graeme, 1997. Context as a spurious concept. Paper presented at the AAAI-97 Fall Symposium on Context in Knowledge Representation and Natural Language, Massachusetts Institute of Technology, Cambridge, MA.

Hobbs, Jerry, 1990. Against confusion. In: J. Hobbs, Literature and cognition, 9-32. CSLI Lecture Notes, 21. Stanford, CA: Center for the Study of Language and Information.

Hymes, Dell, 1972. On communicative competence. In: J. Pride and J. Holmes, eds., Sociolinguistics, 269-293. Harmondsworth: Penguin.

Hymes, Dell, 1974. Foundations of sociolinguistics: An ethnographic approach. Philadelphia, PA: University of Pennsylvania Press.

Hymes, Dell, 1986. Models of interaction of language and social life. In: J. Gumperz and D. Hymes, eds., Directions in sociolinguistics: The ethnography of communication, 35-71. Oxford: Blackwell.

Jahoda, Marie, 1997. Nationalism and world problems. Scientific Austria: 37.

Kessler, Brett, Geoffrey Nunberg and Hinrich Schütze, 1997. Automatic detection of text genre. Manuscript number cmp-lg/9707002. The Computation and Language E-print Archive (http: $/ / \mathrm{xxx}$.lanl.gov/cmp-lg/).

Leech, Geoffrey, 1981. Semantics: The study of meaning. Harmondsworth: Penguin.

Lyons, John, 1995. Linguistic semantics: An introduction. Cambridge: Cambridge University Press.

McCarthy, John, 1987. Generality in artificial intelligence. Communications of the ACM 30(12): 1030-1035.

McCarthy, John and Saša Buvač, 1997. Formalizing context (expanded notes). In: A. Aliseda, R. van Glabbeek and D. Westerståhl, eds., Computing natural language. Stanford, CA: Center for the Study of Language and Information.

Ochs, Elinor, 1990. Indexicality and socialization. In: J. Stigler, R. Shweder and G. Herdt, eds., Cultural psychology: Essays on cooperative human development, 287-308. Cambridge: Cambridge University Press.

Sacks, Harvey, 1992. Games: Legal and illegal actions. In: H. Sacks, Lectures on conversation: I, 473-478. Oxford: Blackwell. [Edited by G. Jefferson; with an introduction by E. Schegloff.]

Schegloff, Emanuel, 1991. In another context. In: A. Duranti and C. Goodwin, eds., Rethinking context: Language as an interactive phenomenon, 191-227. Cambridge: Cambridge University Press.

Silverstein, Michael, 1992. The indeterminacy of contextualization: When is enough enough? In: P. Auer and A. Di Luzio, eds., The contextualization of language, 55-76. Amsterdam: John Benjamins. 
Suzuki, Takao, 1984. Words in context: A Japanese perspective on language and culture (translated by A. Miura). Tokyo: Kodansha.

Winograd, Terry, 1990. Thinking machines: Can there be? Are we? In: D. Partridge and Y. Wilks, eds., The foundations of artificial intelligence: A sourcebook, 167-189. Cambridge: Cambridge University Press.

Varol Akman is a Professor in the Department of Computer Engineering and Information Science at Bilkent University in Ankara. His current research is focused on artificial intelligence approaches to understanding the notion of context. More generally, he is interested in the philosophies of language and mind. From 1980 to 1985 , Akman was a Fulbright scholar at Rensselaer Polytechnic Institute, Troy, New York, where he received a Ph.D. degree in computer and systems engineering. Prior to joining Bilkent in 1988, he held a senior researcher position with the Center for Mathematics and Computer Science and a visiting position with the University of Utrecht, both in the Netherlands. 